\title{
Informed decision making and psychosocial outcomes in pregnant and nonpregnant women offered population fragile $X$ carrier screening
}

\author{
Sylvia A. Metcalfe, BSc, PhD ${ }^{1,2}$, Melissa Martyn, BSc, PhD ${ }^{1}$, Alice Ames, BSc, PhD ${ }^{1,2}$, \\ Vicki Anderson, MA, PhD ${ }^{1,2,3}$, Alison D. Archibald, Grad Dip Gen Couns, PhD ${ }^{1,2,4}$, \\ Rob Carter, $\mathrm{PhD}^{5}$, Jonathan Cohen, $\mathrm{MBBS}^{6}$, Megan Cotter, BSc, MGenCouns ${ }^{1,7}$, \\ William Dang, $\mathrm{BSc}^{8}$, Martin B. Delatycki, MBBS, PhD ${ }^{1,2,4}$, Susan Donath, BSc, MA ${ }^{1,2}$, \\ Samantha Edwards, PGrad Dip Educ, Grad Dip Gen Couns ${ }^{9}$, Robin Forbes, Grad Dip Gen Couns ${ }^{4}$, \\ Mioara Gavrila, MMedSci ${ }^{8}$, Jane Halliday, BSc, PhD ${ }^{1,2}$, Chriselle Hickerton, MHealthSci(GenCouns) ${ }^{1}$, \\ Melissa Hill, Grad Dip Gen Couns, PhD ${ }^{1,10}$, Lorilli Jacobs, MSc, PGrad Dip Ultrasound ${ }^{9}$, \\ Vicki Petrou, BSc, Grad Dip Gen Couns ${ }^{1}$, Loren Plunkett, BSc, MGenCouns ${ }^{1}$, \\ Leslie Sheffield, MBBS, FRACP ${ }^{1,4,11}$, Alison Thornton, Grad Dip Gen Couns ${ }^{1}$, \\ Sandra Younie, BEcon, PGrad Dip HIth Econ ${ }^{5}$ and Jon D. Emery, MBBCH, DPhil ${ }^{9,12}$
}

\begin{abstract}
Purpose: Population-based carrier screening for fragile $\mathrm{X}$ syndrome (FXS) is still not universally endorsed by professional organizations due to concerns around genetic counseling for complex information and potential for psychosocial harms.

Methods: We determined uptake levels, decision making, and psychosocial impact in a prospective study of pregnant and nonpregnant Australian women offered FXS carrier screening in clinical settings. Women received pretest genetic counseling, and completed questionnaires when deciding and one month later.
\end{abstract}

Results: Of 1,156 women recruited, $83.1 \%$ returned the first questionnaire with $70.6 \%$ nonpregnant and $58.8 \%$ pregnant women choosing testing $\left(\chi^{2}=16.98, P<0.001\right)$. Overall, informed choice was high in both nonpregnant $(77.4 \%)$ and pregnant $(72.9 \%)$ women $\left(\chi^{2}=0.21, P=0.644\right)$, and more tested $(76.0 \%)$ than nottested $(66.7 \%)$ women $\left(\chi^{2}=6.35, P=0.012\right)$ made an informed choice. Measures of depression, stress, and anxiety were similar to population norms for $\sim 85 \%$ of women. Decisional conflict and regret were generally low; however, decisional uncertainty and regret were greater in pregnant than nonpregnant women, and not-tested than tested women (uncertainty: $\chi^{2}=18.51, P<0.001$ and $\chi^{2}=43.11, P<0.001$, respectively; regret: $\chi^{2}=6.61, P<0.037$ and $\chi^{2}=35.54, P<0.001$, respectively).

Conclusion: We provide evidence to inform guidelines that population FXS carrier screening can be implemented with minimal psychosocial harms following appropriate information and prescreening genetic counseling.

Genet Med advance online publication 29 June 2017

Key Words: fragile X syndrome; informed choice; informed decision making; population carrier screening; psychosocial outcomes

\section{INTRODUCTION}

Population carrier screening can identify carriers of autosomal or X-linked recessive conditions and provide them with their risk of having affected children. Guidelines have previously determined criteria for inclusion of conditions in population screening. ${ }^{1}$ Fragile X syndrome (FXS) is the most common cause of inherited intellectual and developmental disability with concomitant medical, social, and behavioral problems. Despite FXS meeting many of the criteria to justify population screening, carrier screening for FXS in individuals who have no family or relevant health history has generally not been recommended. ${ }^{2}$ This is because of anticipated difficulties around counseling and education for such a complex X-linked condition. ${ }^{2,3}$ FXS is due to functional loss of FMRP (fragile X mental retardation protein), in most cases caused by hypermethylation of a CGG repeat expansion in the 5' untranslated region (5'UTR) of the FMR1 gene (MIM 309550). A woman who is a carrier of FXS (premutation

${ }^{1}$ Murdoch Childrens Research Institute, Melbourne, Victoria, Australia; ${ }^{2}$ Department of Paediatrics, The University of Melbourne, Melbourne, Victoria, Australia; ${ }^{3}$ Royal Children's Hospital, Melbourne, Victoria, Australia; ${ }^{4}$ Victorian Clinical Genetics Services, Melbourne, Victoria, Australia; ${ }^{5}$ aculty of Health, Deakin Health Economics, Deakin University, Melbourne, Victoria, Australia; ${ }^{6}$ Fragile X Alliance Clinic and Centre for Developmental Disability Health Victoria, Monash University, Melbourne, Victoria, Australia; ${ }^{7}$ Austin Health, Melbourne, Victoria, Australia; ${ }^{8}$ Australian Clinical Labs (formerly Healthscope Pathology), Clayton, Victoria, Australia; ${ }^{9}$ School of Primary Aboriginal and Rural Health Care, University of Western Australia; ${ }^{10}$ Great Ormond Street Hospital for Children, London, UK; ${ }^{11}$ MyDNA Life Australia, Melbourne, Victoria, Australia; ${ }^{12}$ Department of General Practice, The University of Melbourne, Melbourne, Victoria, Australia. Correspondence: Sylvia A. Metcalfe (sylvia.metcalfe@mcri.edu.au) 
(PM): 55-200 CGG repeats) has a reproductive risk for having an affected child with the full mutation (FM: > 200 CGG repeats). ${ }^{4}$ Beyond explaining this pattern of inheritance, additional genetic counseling challenges include a highly variable phenotype in offspring, and personal health risks to carrier women, including an increased risk for fragile $\mathrm{X}$-associated primary ovarian insufficiency syndrome, ${ }^{5}$ fragile $\mathrm{X}$-associated tremor ataxia syndrome, ${ }^{6}$ and other more subtle neurobehavioral features. ${ }^{7}$ Nevertheless, population-based carrier screening of FXS has been occurring in clinical practice for some time. ${ }^{8}$ The American College of Obstetricians and Gynecologists has suggested that it be available to women from the general population who request it, ${ }^{9}$ whereas the Royal Australian and New Zealand College of Obstetricians and Gynaecologists has said that it may be offered to women from the general population periconceptionally and that women should be appropriately informed of the benefits and limitations of testing. ${ }^{10}$ However, its inclusion in recently introduced expanded carrier screening panels has raised some concerns. ${ }^{11}$

Several studies have shown that health professionals, ${ }^{12,13}$ the general population, ${ }^{14,15}$ and families with $\mathrm{FXS}^{16,17}$ are generally in favor of carrier screening for this condition, with a preference for this to occur preconceptionally; however, health professionals consider testing in pregnancy to afford the most pragmatic timing. ${ }^{12,18}$ The primary purpose of carrier screening is to facilitate reproductive choices through a process of informed decision making. ${ }^{1,19}$ There has been a recognized need for research on population carrier screening with a focus on informed decision making and the psychosocial impacts of being offered screening and receiving carrier results, rather than reporting uptake of testing alone. ${ }^{1-3,20}$ Yet few studies have collected comprehensive data on the psychosocial aspects and informed decision making. Only our pilot study ${ }^{21}$ with nonpregnant women and a small retrospective study ${ }^{15}$ have examined informed decision making systematically.

Here we report the findings of a large prospective cohort study in which FXS carrier screening (which can be considered an intervention) was offered to pregnant and nonpregnant women in the general population and comparing uptake of testing, informed decision making and psychosocial impact, and predictors of uptake. Because of the routine nature of various types of testing that women undergo in pregnancy, especially for Down syndrome, ${ }^{22}$ the greater perceived relevance and easier opportunities to offer carrier testing to pregnant women, ${ }^{18}$ and the greater pressures to make quick decisions about testing during pregnancy, we tested two hypotheses: (i) an offer of carrier screening for FXS will result in a higher uptake of testing by pregnant women compared with nonpregnant women and (ii) a lower proportion of pregnant women will make an informed decision about carrier screening compared with nonpregnant women.

\section{MATERIALS AND METHODS}

\section{Overview of study design}

The detailed protocol of this study has been published previously. ${ }^{23}$ A program evaluation approach was used. Study participants were offered FXS carrier screening and asked to complete two questionnaires about their decision: at the time of making the decision (Q1) and one month later (Q2). Interviews were also conducted with selected participants, including carriers, at several time-points and with staff from clinics offering the study after completion of the study. Qualitative interview data will be published separately.

Ethics approval was granted by the Human Research Ethics Committees of the Universities of Melbourne and Western Australia and by recruiting clinics, where required. All participants gave written consent.

\section{Overview of recruitment}

Women aged 18-70 who were either not pregnant or up to 13 weeks pregnant were recruited from general (family) practice, public and private obstetric, and private obstetric ultrasound clinics in two Australian cities: Melbourne, Victoria (Vic) and Perth, Western Australia (WA). Women were invited into the study using either a direct or indirect approach (see Supplementary Table S1 online). With both approaches, women receiving the study pack were deemed to have consented (i.e., agreed to participate) and spoke with a research genetic counselor (face to face or over the telephone) to facilitate deliberation about testing. There was no charge to women for the test.

Participants were asked to return Q1 with a used/unused sample collection kit once they had made their decision about testing. Pregnant women were sent a text (SMS) reminder to return Q1 one week after agreeing to participate. Nonpregnant women were sent an SMS reminder after 3 weeks, a letter after 6 weeks, and a final phone call/letter after 10 weeks. Q2 was sent to women who returned Q1 approximately one month later or after test results were returned to participants, with SMS/letter reminders sent at 6 and 10 weeks post-Q1 return.

\section{Data collection}

Q1 contained a number of validated and psychometrically robust self-report scales measuring knowledge, using a scale designed specifically for the study; ${ }^{24}$ attitudes; ${ }^{25}$ deliberation; ${ }^{26}$ depression, anxiety, and stress (Depression Anxiety Stress Scale, DASS); ${ }^{27}$ anxiety (Spielberger State-Trait Anxiety Inventory, STAI); ${ }^{28}$ decisional conflict; ${ }^{29}$ willingness to pay (ranging from AUD0 to AUD400); and items measuring health beliefs (including statements about perceived severity, susceptibility, benefits, and barriers, ${ }^{30}$ as well questions derived from our previous study ${ }^{17}$ ). Sociodemographic information was also collected: age, education, marital status, parity, post code (enabling socioeconomic inferences), reproductive life stage, family history of FXS, and associated conditions or intellectual disability/significant learning problems/autism spectrum disorder. Q2 contained the same knowledge, DASS and STAI scales, and a decisional regret scale. ${ }^{31}$

\section{Molecular testing}

For a description of the molecular testing conducted for FXS, see Supplementary Methods S1. Women who received a test 


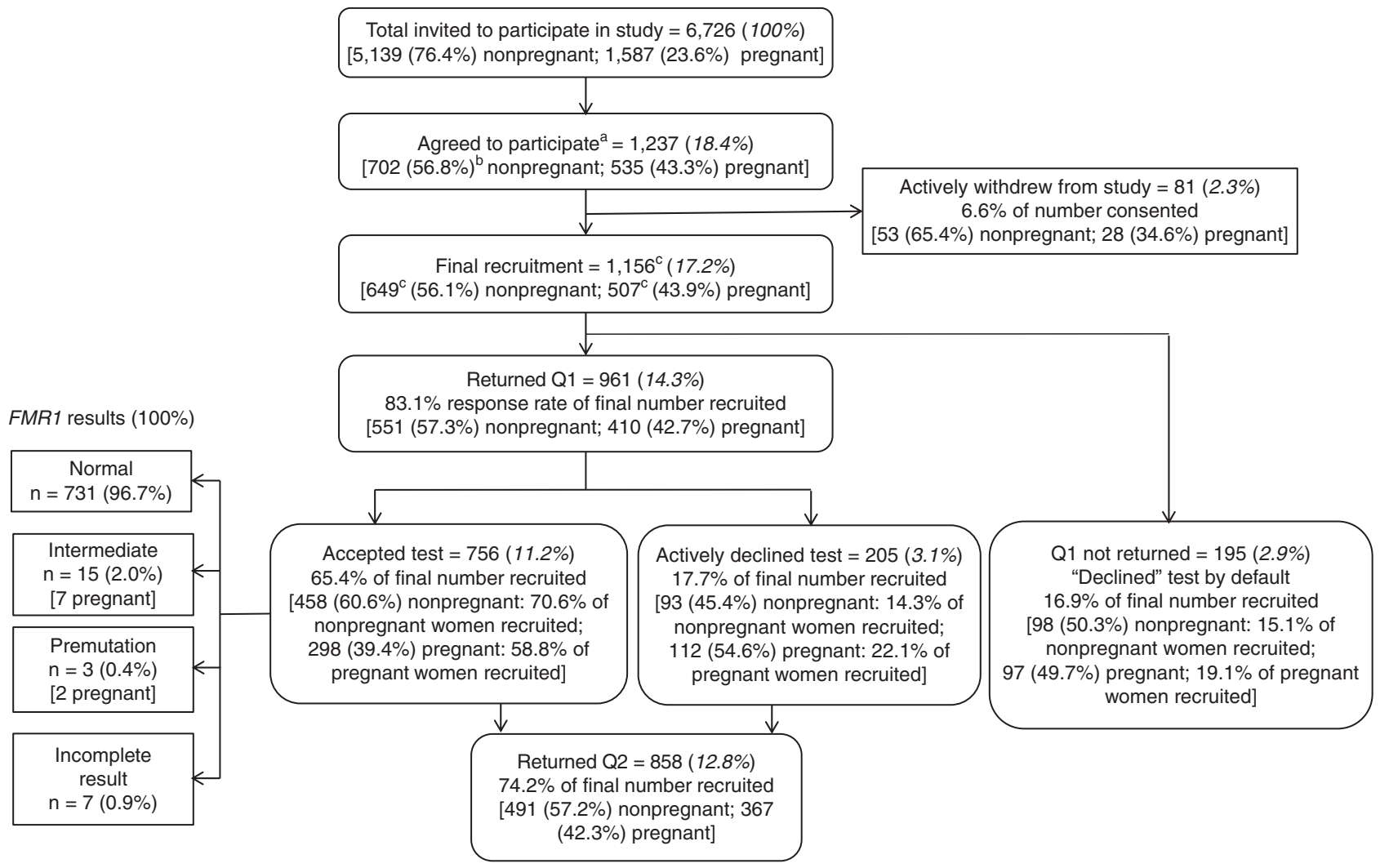

Figure 1 Numbers and response rates of participants at different stages of the study.

result in the normal range (test-negative: CGG repeats $<45$ ) were sent a letter by mail that included an offer to speak to a genetic counselor at their local clinical service. Women with a test-positive result (gray zone (GZ), 45-54; PM, 55-200; FM, $>200$ repeats) were telephoned with their result by a clinical genetics service and offered a face-to-face appointment.

\section{Data analysis}

The primary outcomes for the study were test uptake and informed choice. We report uptake of FXS testing as the percentage of women returning Q1 who chose to have carrier testing. The denominator was all women who received the study pack who did not subsequently actively withdraw from the study; i.e., the denominator includes women who failed to return Q1, as they can be considered insufficiently motivated to want testing to complete and return the questionnaire (declined by default). For a description of how the study was powered and standard statistical analysis performed see Supplementary Methods S2.

To compare uptake of testing by pregnant and nonpregnant women, we used univariate analyses with uptake as the dependent variable to investigate whether any of the questions asked in Q1 were predictors of uptake. To ensure that difference in uptake was not due to differences in the composition of the pregnant and nonpregnant samples, adjusted analyses were performed using multivariable logistic regression to adjust for potential confounding sociodemographic variables found to be different between pregnant and nonpregnant women.

\section{RESULTS}

Recruitment and sociodemographic characteristics

These findings represent the quantitative short-term outcome data described in the program evaluation logic model for this study. ${ }^{23}$ As shown in Figure 1, a total of 6,726 women were invited to participate (76.4\% nonpregnant; $23.6 \%$ pregnant) between July 2009 and April 2013 who were patients at 24 different centers (Supplementary Table S1). Of these, 2,135 (1,058 nonpregnant and 1,077 pregnant women) were invited to participate in person (direct approach) and 4,591 (4,079 nonpregnant and 512 pregnant women) received a mail-out letter from the clinic (indirect approach) - see Supplementary Table S1. Estimated time for a research genetic counselor to discuss the study/test with women following their recruitment was between 5 and $30 \mathrm{~min}$. Note that initially the focus was on recruiting nonpregnant women and, once the new test was validated in these women, pregnant women were also recruited. Figure 1 and Supplementary Table $\mathbf{S} 1$ report the numbers and percentages of women who were recruited and returned Q1 and Q2.

Sociodemographic data of women who returned Q1 are shown in Supplementary Table S2. Women participating in 
the study overall had a higher level of education than women of the same age range in the general population. ${ }^{32}$ Pregnant women were more highly educated than nonpregnant women but there was no difference in Socio-Economic Indexes for Areas rankings for the pregnant and nonpregnant women in our study (Supplementary Table S2).

\section{Test uptake and results}

Overall $65.4 \%(n=756)$ of women recruited chose to be tested (Figure 1). A greater percentage of nonpregnant women $(70.6 \%, \mathrm{n}=458)$ was tested than pregnant women $(58.8 \%$, $\left.\mathrm{n}=298 ; \chi^{2}=16.98, \quad P<0.001\right)$, and a greater percentage recruited by the indirect approach was tested $(77.7 \%$, $\mathrm{n}=192)$ than the direct approach (62.1\%, $\mathrm{n}=564$; $\left.\chi^{2}=20.43, P<0.001\right)$, see Supplementary Table S1. However, recruitment rate was higher with the direct approach $(42.6 \%, \mathrm{n}=909)$ compared with the indirect approach $(5.4 \%$, $\left.\mathrm{n}=247 ; \chi^{2}=1508.41, P<0.001\right)$, and the number of pregnant women recruited indirectly (by letter) was very small (Supplementary Table S1).

FMR1 test outcome results are shown in Figure 1. In seven cases (out of $756 ; 0.9 \%$ ) a result could not be determined owing to insufficient DNA and/or failed result without the possibility of a re-collection in the timeframe allowed by the Human Research Ethics Committees approval. A PM result was found in 1 in $252(0.04 \%$, 95\% CI (0.14-1.16)) women tested $(58,62$, and 64 CGG repeats), a GZ result in 1 in 50 (1.98\%, 95\% CI (1.21-3.25)) women, and no women were found to have a FM result (Figure 1).

\section{Decision making and informed choice}

Table 1 shows the individual components of the multidimensional measure of informed choice (MMIC; knowledge, attitudes, and test uptake) with the additional measure of deliberation reported in Q1. Overall, 85.0\% of women in the study had good knowledge and $72.9 \%$ had positive attitudes to testing for themselves. Almost three-quarters of participants were classified as having made an informed choice. There was no evidence of a difference in the percentages of pregnant versus nonpregnant women who made an informed choice (Table 1), having adjusted for sociodemographic differences between these two groups (adjusted odds ratio (OR) 0.9, 95\% CI (0.67-1.22), $P=0.506)$. Women who chose to be tested were significantly more likely to make an informed choice compared with those who were not tested. Poor knowledge accounted for about half the women who did not make an informed choice, while mismatched attitudes and behavior (i.e., test uptake) accounted for the other half (data not shown). Overall, $87.9 \%$ of women deliberated about their decision to be tested, with no evidence of differences between the groups.

Supplementary Table S3 shows participants' responses to questions around the time taken to make the decision as to whether to be tested, whether other people were involved in the decision making, and whether they changed their mind from the initial decision. In making their decision, 95\% reported that they read the study brochure while only $10 \%$ looked at the study website, which included videos of people with varying degrees of severity, or other websites. Participants' responses to additional questions about having heard of FXS previously, having a family history of, or knowing someone with, FXS and other learning disabilities, or having a personal experience of infertility/early menopause/ irregular menstruation are also shown in Supplementary Table S3.

\section{Psychosocial measures}

Table 2 shows women's responses to the DASS and STAI in Q1 and Q2, while Table 3 shows responses to decisional conflict scales in Q1 and decisional regret in Q2. Overall, the majority of women reported normal depression, anxiety, and stress scores in Q1 and Q2 (Table 2). Pregnant women were less depressed and stressed compared with nonpregnant women (Q1 and Q2), while more pregnant women were less anxious (DASS) in Q2. More tested women were less anxious (DASS) at the time of making the decision than women who were not tested (Q1), with this difference diminishing in Q2. Overall, there was no evidence of a difference in Q2 DASS scores between women who declined testing, women who were tested and received a normal result, and women who received a test-positive result (see footnote to Table 2 ). Of the test-positive women, one woman with a GZ result had a higher than normal score for all three DASS scales in Q1, which further increased in Q2; one woman with a GZ result had an increased anxiety score in Q2; and one woman with a PM result had increased depression and stress scores in Q2. All three women were pregnant. Two women with a GZ result had DASS scores that decreased in Q2 (one pregnant, one not).

Overall, decisional conflict was low with no difference between nonpregnant and pregnant women; however, decisional conflict was greater in women who declined testing compared with women who chose testing (Table 3 ). There was greater uncertainty in pregnant women compared with nonpregnant women and in women who were not tested compared with those tested. The majority of women had low decisional regret (Table 3). More pregnant women regretted their decision compared with nonpregnant women, and more women who declined testing regretted their decision compared with women who were tested (Table 3). Women who tested positive had similar decisional regret to those who declined testing, and both these groups had greater regret compared with women who were tested and had a normal result (see footnote to Table 3 ). Of the 14 test-positive women who completed Q2, three women with a GZ and one woman with a PM result had scores in the moderate to strong regret category, and all four were pregnant.

\section{Predictors of testing}

After adjusting for sociodemographic differences between pregnant and nonpregnant women, greater odds of being tested were associated with having a positive attitude to 
Table 1 Measures of informed choice obtained from responses to questionnaire $1(N=961)$

Measure

Women's status

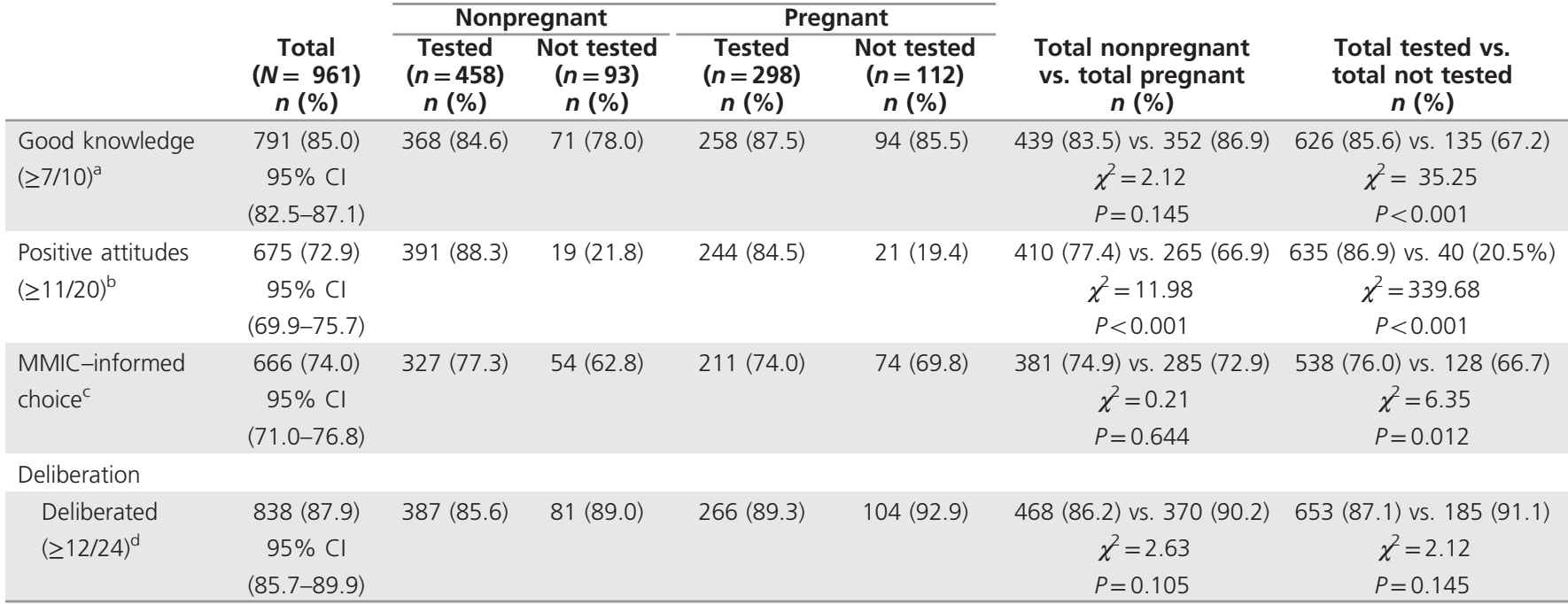

${ }^{a}$ Not all women completed the knowledge scale: nonpregnant, tested $n=435$; nonpregnant, not tested $n=91 ;$ pregnant, tested $n=295$; pregnant, not tested $n=110$. ${ }^{b}$ Not all women completed the attitudes scale: nonpregnant, tested $n=443$; nonpregnant, not tested $n=87$; pregnant, tested $n=288$; pregnant, not tested $n=108$. ${ }^{\mathrm{C}} \mathrm{MMIC}=$ multidimensional model of informed choice. Informed choice = good knowledge, positive attitudes, tested or good knowledge, poor attitudes, not tested. Because not all women completed the knowledge or the attitudes scales, the MMIC is shown for the lowest number of women who completed both scales: nonpregnant, tested $n=423$; nonpregnant, not tested $n=86$; pregnant, tested $n=285$; pregnant, not tested $n=106$. dNot all women completed the deliberation scale: nonpregnant, tested $n=452$; nonpregnant, not tested $n=91$.

testing for themselves (OR 25.63, $\mathrm{n}=926,95 \%$ CI (17.0438.57), $P<0.001)$; having a positive attitude to carrier testing being available to all women (OR 11.34, $\mathrm{n}=956,95 \%$ CI (5.22-24.66), $P<0.001)$; having a personal history of irregular periods (OR 1.73, $\mathrm{n}=942,95 \%$ CI $(1.21-2.47), P=0.003$ ); and believing that FXS is a severe condition, anyone could be a carrier, and acknowledging the importance of health for themselves and their children (Health Beliefs Factor 1: OR 3.9, $\mathrm{n}=760,95 \%$ CI (3.04-4.99), $P<0.001)$ - see Supplementary Table S4 for description of these questions and factors. Lower odds of being tested were associated with being pregnant (adjusted OR 0.56, $\mathrm{n}=942,95 \%$ CI $(0.39-0.8), P=0.001)$; having someone else involved in making the decision (OR $0.57, \mathrm{n}=961,95 \% \mathrm{CI}(0.42-0.78), P<0.001)$; taking longer to make the decision (OR 0.18, $\mathrm{n}=958,95 \%$ CI $(0.1-0.38)$, $P<0.001$ ); having high (overall) decisional conflict (OR 0.51, $\mathrm{n}=945,95 \%$ CI $(0.28-0.93), P=0.028)$; having high decisional uncertainty (OR $0.26, \mathrm{n}=954,95 \% \mathrm{CI}(0.17-0.4), P<0.001$ ); and believing that testing was not relevant to them, being worried if found to be a carrier, and the importance of familial disapproval of being tested (Health Beliefs Factor 2: OR 0.23, $\mathrm{n}=760,95 \%$ CI $(0.18-0.3), P<0.001)-$ see Supplementary Table S4 for description of these questions and factors.

\section{DISCUSSION}

Our findings regarding nonpregnant and pregnant women choosing testing and making an informed choice show evidence to the contrary for both the hypotheses we tested. Overall, a higher percentage of nonpregnant women was tested compared with pregnant women, although this also varied according to method of invitation to the study (as shown in Supplementary Table S1), and the majority of women made an informed choice, with no difference between pregnant versus nonpregnant women. Generally, women showed high levels of knowledge around the time of making the decision whether to be tested. A concern expressed around population carrier screening relates to conditions in which the phenotype is variable in severity and not always clearly defined, ${ }^{11}$ as in the case of FXS. All women had spoken with a research genetic counselor, either face to face or by telephone, and were given a detailed information brochure. This brochure had been somewhat refined following our pilot study $;{ }^{21}$ specifically, brief case examples of children with mild, moderate, and severe cognitive and behavioral features of FXS were included, and there was an emphasis on carriers not always having a family history of FXS or intellectual disability. In making their decision, $95 \%$ of women said they had read the study brochure. Collectively, this indicates that both the quality of the brochure information and the interaction with genetic counselors contributed to these high knowledge scores, suggesting these interventions were sufficient to enable understanding of the complexity of information about FXS.

Having a positive attitude to being tested themselves for FXS carrier state had the largest OR, making this the strongest predictor of being tested. While not surprising, the lack of awareness of FXS in the community, as shown by others, ${ }^{14,15,33}$ with almost $75 \%$ of women in our study having never heard of FXS previously, poses a challenge when considering how best to implement offering carrier screening in the general population. This challenge was further demonstrated by the poor participation rate for those who were approached indirectly by letter compared with the direct 
Table 2 Responses to psychosocial measures of DASS and STAI in questionnaires $1(N=961)$ and $2(N=858)$

Measure

Total Q1

Q1 $(N=961)$

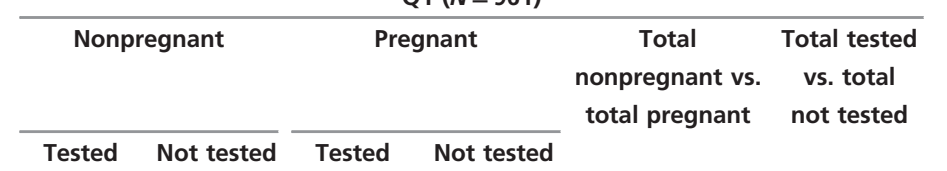

Total Q2

Q2 $(N=858)$

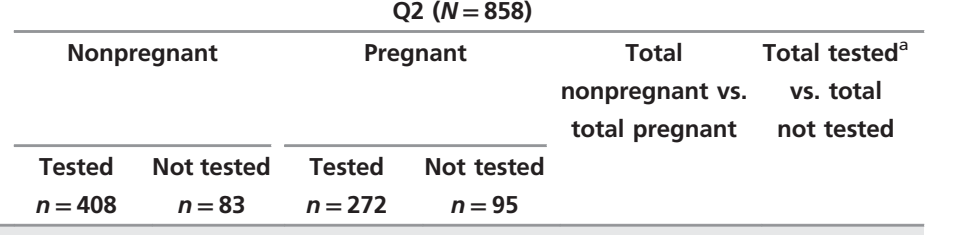

\begin{tabular}{|c|c|c|c|c|c|c|c|c|c|c|c|c|c|c|}
\hline \multirow{2}{*}{\multicolumn{15}{|c|}{ DASS: }} \\
\hline & & & & & & & & & & & & & & \\
\hline \multirow[t]{2}{*}{$\begin{array}{l}\text { Depression- } \\
\text { normal }^{\text {b. }} n(\%)\end{array}$} & $\begin{array}{c}804(84.9) \\
95 \% \mathrm{Cl} \\
(82.5-87.0)\end{array}$ & $356(79.5)$ & 77 (84.6) & $271(91.3)$ & $100(90.1)$ & $\begin{array}{c}433 \text { (80.3) vs. } \\
371 \text { (90.9) }\end{array}$ & $\begin{array}{c}627 \text { (84.2) vs. } \\
177 \text { (87.6) }\end{array}$ & $\begin{array}{c}751(87.9) \\
95 \% \mathrm{Cl} \\
(85.6-90.0)\end{array}$ & $344(84.7)$ & 71 (85.5) & $250(92.3)$ & $86(90.5)$ & $\begin{array}{c}415 \text { (84.9) vs. } \\
336 \text { (92.1) }\end{array}$ & $\begin{array}{c}594 \text { (87.9) vs. } \\
157 \text { (88.2) }\end{array}$ \\
\hline & & & & & & $\begin{array}{l}\chi^{2}=18.51 \\
P<0.001\end{array}$ & $\begin{array}{l}\chi^{2}=1.22 \\
P=0.268\end{array}$ & & & & & & $\begin{array}{l}\chi^{2}=9.51 \\
P=0.002\end{array}$ & $\begin{array}{l}\chi^{2}=0.00 \\
P=1.000\end{array}$ \\
\hline \multirow[t]{2}{*}{$\begin{array}{l}\text { Anxiety—normal } \\
n(\%)\end{array}$} & $\begin{array}{c}804(84.3) \\
95 \% \mathrm{Cl} \\
(81.9-86.5)\end{array}$ & $368(81.6)$ & $79(85.5)$ & $258(86.9)$ & $74(86.5)$ & $\begin{array}{c}447 \text { (82.5) vs. } \\
354 \text { (86.8) }\end{array}$ & $\begin{array}{l}626 \text { (83.7) vs. } \\
153(75.7)\end{array}$ & $\begin{array}{c}747(87.4) \\
95 \% \mathrm{Cl} \\
(85.0-89.4)\end{array}$ & $342(84.2)$ & $73(88.0)$ & $246(90.4)$ & $86(91.5)$ & $\begin{array}{c}415 \text { (84.5) vs. } \\
332(90.7)\end{array}$ & $\begin{array}{c}588 \text { (86.7) vs. } \\
159 \text { (89.3) }\end{array}$ \\
\hline & & & & & & $\begin{array}{l}\chi^{2}=2.93 \\
p=0.087\end{array}$ & $\begin{array}{l}\chi^{2}=5.88 \\
p=0.015\end{array}$ & & & & & & $\begin{array}{l}\chi^{2}=5.96 \\
p=0.015\end{array}$ & $\begin{array}{l}\chi^{2}=0.96 \\
p=0.327\end{array}$ \\
\hline \multirow[t]{2}{*}{$\begin{array}{l}\text { Stress—-normal } \\
n(\%)\end{array}$} & $\begin{array}{c}812(85.4) \\
95 \% \mathrm{Cl} \\
(81.9-86.5)\end{array}$ & $370(81.5)$ & $78(85.7)$ & 266 (89.9) & $98(89.1)$ & $\begin{array}{c}448 \text { (82.2) vs. } \\
364 \text { (89.7) }\end{array}$ & $\begin{array}{c}636 \text { (84.8) vs. } \\
176 \text { (87.6) }\end{array}$ & $\begin{array}{c}747(87.6) \\
95 \% \mathrm{Cl} \\
(85.2-89.6)\end{array}$ & $343(84.7)$ & $67(81.7)$ & $248(91.5)$ & $89(93.7)$ & $\begin{array}{c}410(84.2) \text { vs. } \\
337(92.1)\end{array}$ & $\begin{array}{c}591 \text { (87.4) vs. } \\
156 \text { (88.1) }\end{array}$ \\
\hline & & & & & & $\begin{array}{l}\chi^{2}=9.77 \\
p=0.002\end{array}$ & $\begin{array}{l}\chi^{2}=0.76 \\
p=0.383\end{array}$ & & & & & & $\begin{array}{l}\chi^{2}=11.23 \\
p<0.001\end{array}$ & $\begin{array}{l}\chi^{2}=0.02 \\
p=0.899\end{array}$ \\
\hline $\begin{array}{l}\text { STAI: Anxiety } \\
(0-80)^{e} \text { : Mean } \\
\text { (s.d.) }\end{array}$ & $\begin{array}{c}36.5(12.2) \\
95 \% \mathrm{Cl} \\
(36.7-37.3)\end{array}$ & $36.3(13.2)$ & $38.7(11.3)$ & $36.1(11.4)$ & $36.7(10.7)$ & $\begin{array}{c}36.7 \text { (12.9) vs. } \\
36.2(11.2) \\
t=0.623 \\
p=0.533\end{array}$ & $\begin{array}{c}36.2(12.5) \text { vs. } \\
37.6(11.0) \\
t=1.45 \\
p=0.147\end{array}$ & $\begin{array}{c}34.0(11.3) \\
95 \% \mathrm{Cl} \\
(33.2-34.8)\end{array}$ & $34.3(12.0)$ & $34.5(10.8)$ & $33.0(10.9)$ & $35.0(9.4)$ & $\begin{array}{c}34.4(11.8) \text { vs. } \\
33.5(10.6) \\
t=1.151 \\
p=0.25\end{array}$ & $\begin{array}{c}33.8(11.6) \text { vs. } \\
34.7(10.1) \\
t=0.95 \\
p=0.345\end{array}$ \\
\hline
\end{tabular}

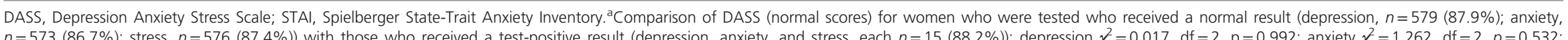
$n=573(86.7 \%)$; stress, $n=576(87.4 \%))$ with those who received a test-positive result (depression, anxiety, and stress, each $n=15(88.2 \%)):$ depression $\chi^{2}=0.017, \mathrm{df}=2, p=0.992 ;$ anxiety $\chi^{2}=1.262, \mathrm{df}=2, p=0.532$; stress $\chi^{2}=0.075, \mathrm{df}=2, p=0.963$. ${ }^{b}$ Not all women completed the depression scale of DASS; Q1: nonpregnant, tested $n=448$; nonpregnant, not tested $n=91$; pregnant, tested $n=297$; pregnant, not tested $n=111$; Q2: nonpregnant, tested $n=406$; nonpregnant, not tested $n=83$; pregnant, tested $n=270$; pregnant, not tested $n=95$. 'Not all women completed the anxiety scale of DASS; Q1: nonpregnant, tested $n=451$; nonpregnant, not tested $n=91$; pregnant, tested $n=297$; pregnant, not tested $n=111$; Q2; nonpregnant, tested $n=406$; nonpregnant, not tested $n=83$; pregnant, tested $n=272$; pregnant, not tested $n=94$. ${ }^{\mathrm{d} N o t}$ all women completed the stress scale of DASS; Q1: nonpregnant, tested $n=454$; nonpregnant, not tested $n=91$; pregnant, tested $n=296$; pregnant, not tested $n=110$; Q2: nonpregnant, tested $n=405$; nonpregnant, not tested $n=82$;

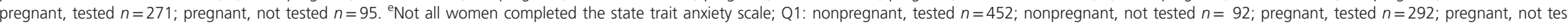
ted $n=112$; Q2: nonpregnant, tested $n=404$; nonpregnant, not tested $n=83$; pregnant, tested $n=271$; pregnant, not tested $n=95$. STAl norm average is 31-49. 
Table 3 Responses to decisional conflict scales (Q1, $N=961)$ and decisional regret scale $(\mathrm{Q} 2, N=858)$

\begin{tabular}{|c|c|c|c|c|c|c|c|c|c|c|c|}
\hline \multirow[t]{2}{*}{ Measure } & \multirow[t]{2}{*}{ Total } & \multicolumn{2}{|c|}{ Nonpregnant } & \multicolumn{2}{|c|}{ Pregnant } & \multirow{2}{*}{$\begin{array}{c}\text { Total } \\
\text { nonpregnant }\end{array}$} & \multirow{2}{*}{$\begin{array}{c}\text { Total } \\
\text { pregnant }\end{array}$} & \multirow{2}{*}{$\begin{array}{l}\text { Total nonpregnant vs. } \\
\text { pregnant: trend across } \\
\text { all score categories }\end{array}$} & \multirow{2}{*}{$\begin{array}{c}\text { Total } \\
\text { tested }\end{array}$} & \multirow{2}{*}{$\begin{array}{l}\text { Total not } \\
\text { tested }\end{array}$} & \multirow{2}{*}{$\begin{array}{l}\text { Total tested vs. not } \\
\text { tested: trend across } \\
\text { all score categories }\end{array}$} \\
\hline & & Tested & $\begin{array}{c}\text { Not } \\
\text { tested }\end{array}$ & Tested & $\begin{array}{l}\text { Not } \\
\text { tested }\end{array}$ & & & & & & \\
\hline \multicolumn{12}{|l|}{ Decisional conflict scale ${ }^{b}$} \\
\hline Score 0-24: $n(\%)$ & $537(56.8)$ & $279(62.2)$ & $38(42.2)$ & $163(55.4)$ & $57(51.4)$ & $317(58.7)$ & $220(54.3)$ & $x^{2}=2.37$ & $442(59.4)$ & $95(47.3)$ & $x^{2}=9.52$ \\
\hline Score 25-37.5: $n(\%)$ & 347 (36.7) & $145(32.2)$ & $42(46.7)$ & $112(38.1)$ & $48(43.2)$ & $187(34.6)$ & $160(39.5)$ & $d f=2$ & $257(34.5)$ & $90(44.8)$ & $\mathrm{df}=2$ \\
\hline Score > 37.5-100: $n(\%)$ & $61(6.5)$ & $26(5.8)$ & $10(11.1)$ & $19(6.5)$ & $6(5.4)$ & $36(6.7)$ & $25(6.2)$ & $p=0.306$ & $45(6.1)$ & $16(8.0)$ & $p=0.009$ \\
\hline \multicolumn{12}{|c|}{ Decisional conflict uncertainty subscale ${ }^{c}$} \\
\hline Score 0-24: $n(\%)$ & $430(45.1)$ & $246(54.1)$ & $29(32.2)$ & $126(42.4)$ & $29(25.9)$ & $275(50.5)$ & $155(37.9)$ & $x^{2}=18.52$ & $372(46.8)$ & $589(28.7)$ & $\chi^{2}=43.11$ \\
\hline Score $25-37.5: n(\%)$ & $347(36.4)$ & $154(33.9)$ & $35(38.9)$ & $115(38.7)$ & $43(38.4)$ & $189(34.7)$ & $158(38.6)$ & $d f=2$ & $269(35.8)$ & 78 (38.6) & $d f=2$ \\
\hline Score > 37.5-100: $n(\%)$ & $177(18.6)$ & $55(12.1)$ & $26(28.9)$ & $56(18.9)$ & $40(35.7)$ & $81(14.9)$ & $96(23.5)$ & $p<0.001$ & $111(14.8)$ & $66(32.7)$ & $p<0.001$ \\
\hline \multicolumn{12}{|l|}{ Decisional regret scale ${ }^{d}$} \\
\hline Score $0: n(\%)$ & $290(40.9)$ & $140(48.3)$ & $17(28.8)$ & $112(42.0)$ & $21(22.6)$ & $157(45.0)$ & $133(36.9)$ & $x^{2}=6.61$ & $252(45.2)$ & $38(25.0)$ & $x^{2}=35.54$ \\
\hline Score 1-25: $n(\%)$ & $344(48.5)$ & $130(44.8)$ & $33(55.9)$ & $133(49.8)$ & $48(51.6)$ & $163(46.7)$ & $181(50.3)$ & $d f=2$ & $263(47.2)$ & $81(53.3)$ & $d f=2$ \\
\hline Score > 25-100: $n(\%)$ & $75(10.6)$ & $20(6.9)$ & $9(15.3)$ & $22(8.2)$ & $24(25.8)$ & $29(8.3)$ & $46(12.8)$ & $p=0.037$ & $42(7.5)$ & $33(21.7)$ & $p<0.001$ \\
\hline \multicolumn{12}{|c|}{ 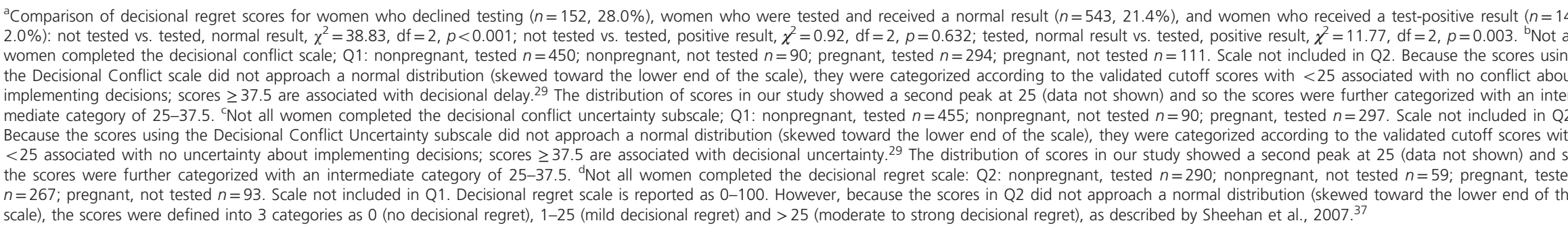 } \\
\hline
\end{tabular}


approach by a research genetic counselor/clinic staff. This poor response to an indirect approach has also been noted for carrier screening for cystic fibrosis ${ }^{34}$ and highlights the importance in clinical practice of a face-to-face interaction to start the conversation about carrier screening and the relative ineffectiveness in general of passive mailed invitations/ marketing. Of course, it may be that the requirement to complete research questionnaires was a barrier to women who might have considered testing but were not interested in participating in research.

Other factors associated with greater odds of being tested were consistent with the Health Belief Model (Supplementary Table S4), including perceived susceptibility, condition severity, and health benefits for themselves and their children in terms of wanting to avoid the potential impact of this on their family's life and on their future children or grandchildren. Conversely, factors associated with not being tested included being pregnant, perceived lack of relevance, worry around being found to be a carrier, and potential familial disapproval. Perceived susceptibility and relevance are closely interrelated; women who chose to be tested generally felt that, because anyone could be a carrier of FXS, they were potentially susceptible and the test was therefore relevant to them. In contrast, being healthy and lacking a family history of FXS or intellectual disability was interpreted as limiting susceptibility and relevance for women who chose not to be tested. Not needing a family history to be at risk of being a carrier was emphasized in our modified brochure and genetic counseling, and remains a clear "takehome message" in the offer of carrier screening. ${ }^{35}$

The aim of reproductive carrier screening is not the same as for newborn screening, for which early diagnosis and treatment is the goal; rather the aim is to facilitate reproductive decision making and autonomy. ${ }^{19}$ Women were given the opportunity to decide in their own time and to return the sample for testing. This home-based testing allowed women the opportunity to deliberate about their decision away from the clinic and without the influence of a health professional. This likely contributed to the high percentage of women who deliberated about their decision (Table 1). While women who chose testing made their decision with greater certainty and faster, it is possible that if the offer of testing and sample collection had occurred simultaneously in the clinic, women who actually chose not to be tested could have felt "pressured" into taking the test. In fact, having someone else involved in the decision making and being less certain about the decision also decreased the odds of being tested. Having time for reflection enhances deliberation, which enables informed decision making, ${ }^{26}$ and this can be facilitated by providing a sample in their own time. Increasingly, genetic testing can be performed on buccal or saliva samples, which in our study had low failure rates and good performance characteristics. Others have suggested that the ease of providing a buccal/ saliva sample might lead women not to weigh-up their decision to be tested, ${ }^{14}$ but that does not appear to be the case here given the high levels of reported deliberation. While our results suggest that the decision itself to be tested can be made outside of a clinic setting, we are not suggesting that the offer and discussion of a carrier test should be independent of a health professional.

There appears to be consensus that, ideally, population carrier screening should occur before a woman is pregnant to maximize the time for decision making and the benefit of providing greater reproductive options, including whether to become pregnant, using donor gametes or preimplantation diagnosis. ${ }^{19}$ However, as we have shown, an offer early in pregnancy can result in informed decision making with the provision of suitable information and opportunity for discussion, such as in the case of a telephone conversation with a genetic counselor. We have demonstrated that, in general, there was minimal psychosocial impact on women offered testing, and women who were tested were in fact less anxious at the time of making the decision. Of the 17 testpositive women, only three women (two GZ and one PM) showed an increase in one or more of the DASS measures at follow-up and, notably, all were pregnant. Greatest decisional regret was reported by pregnant women and by women who were not tested, with four test-positive women (three GZ and one PM) showing moderate to strong regret, all of whom were pregnant. While there were relatively few women who tested positive, we suggest these data emphasize potential benefits of screening prior to pregnancy, despite the prenatal period being a more pragmatic time. We will report further outcomes for these participants as part of the program evaluation component of the study, including willingness-to-pay data. ${ }^{23}$

This study has a number of limitations and we acknowledge these might bias the findings. Participants were self-selected, with relatively high socioeconomic status, and generally highly educated, especially pregnant women, which may have contributed to their high knowledge levels, as well as the possibility that women may have referred to the brochure while completing the knowledge questions. Therefore, the findings are not generalizable to women with lower levels of education and lower socioeconomic status; however, the women in this study may be more indicative of women in Australia who are likely to undertake carrier screening, given that population carrier screening is currently available only as a fee-for-service test and women must pay privately for the test. In fact, the test was offered at no cost to women who participated. Because there was no group of women who were not offered carrier screening, we cannot compare psychosocial measures to a control group, nor did we collect baseline measures. The MMIC has limitations as a measure of informed choice as it does not incorporate reasons for making the decision, which would require a qualitative approach.

This prospective study is the first to provide comprehensive data on informed decision making coupled with psychosocial measures in pregnant and nonpregnant women from the general population offered FXS carrier screening. We have provided evidence that, with appropriate support and counseling, pregnant and nonpregnant women can make informed decisions without concerns of significant adverse 
psychosocial consequences, although effort should be made to engage women to consider the offer of screening before they become pregnant. Our findings critically inform and counter existing recommendations against FXS carrier screening in the general population. , $^{2,36}$

As genetic carrier screening moves from the paradigm of one test-one condition to expanded carrier screening, the European Society of Human Genetics has recommended that appropriate support and counseling is available to facilitate decision making, while acknowledging that providing detailed information about each condition ${ }^{19}$ will not be possible. Our study design can inform future research around expanded carrier screening in which it will be essential to examine similar psychosocial consequences.

\section{SUPPLEMENTARY MATERIAL}

Supplementary material is linked to the online version of the paper at http://www.nature.com/gim

\section{ACKNOWLEDGMENTS}

We acknowledge funding support from National Health and Medical Research Council (NHMRC) Project Grant ID 607320, the Shepherd Foundation, the Helen Macpherson Smith Trust, the Apex Foundation, the Bennelong Foundation, the Fragile $X$ Alliance, and Murdoch Childrens Research Institute. J.H. is funded by an NHMRC Fellowship. J.E. is funded by an NHMRC Practitioner Fellowship. We thank Renee Dow, Annette Opat, Kate Pope, Gabrielle Reid, and Kellie Sullivan for help with recruitment; Jan Hodgson, Belinda McClaren, and Melody Menezes for assistance with pretest counseling; David Francis, Devika Ganesamoorthy, Louise Hills, Erin Turbitt, and Jonathan Whitty for support with molecular testing; and Mark Adams for assistance with data entry.

\section{DISCLOSURE}

The authors declare no conflict of interest.

\section{REFERENCES}

1. Godard B, Leo ten K, Evers-Kiebooms G, Aymé S. Population genetic screening programmes: principles, techniques, practices, and policies. Eur J Hum Genet 2003;11:\$49-S87.

2. Sherman S, Pletcher BA, Driscoll DA. Fragile $X$ syndrome: diagnostic and carrier testing. Genet Med 2005;7:584-587.

3. Finucane B, Abrams L, Cronister A, Archibald AD, Bennett RL, McConkieRosell A. Genetic counseling and testing for FMR1 gene mutations: practice guidelines of the National Society of Genetic Counselors. J Genet Couns 2012;21:752-760.

4. Hagerman R, Hagerman P. Fragile X Syndrome: Diagnosis, Treatment, and Research. Johns Hopkins University Press: Baltimore, Maryland, 2002.

5. Sullivan AK, Marcus M, Epstein MP, et al. Association of FMR1 repeat size with ovarian dysfunction. Hum Reprod 2005;20:402-412.

6. Hagerman RJ, Leehey $M$, Heinrichs $W$, et al. Intention tremor, parkinsonism, and generalized brain atrophy in male carriers of fragile X. Neurology 2001;57:127-130.

7. Kraan CM, Hocking DR, Bradshaw JL, et al. Symbolic sequence learning is associated with cognitive-affective profiles in female FMR1 premutation carriers. Genes Brain Behav 2014;13:385-393.

8. Berkenstadt M, Ries-Levavi L, Cuckle H, Peleg L, Barkai G. Preconceptional and prenatal screening for fragile $X$ syndrome: experience with 40,000 tests. Prenat Diagn 2007;27:991-994.

9. American College of Obstetricians and Gynecologists Committee on Genetics. ACOG committee opinion no. 469: carrier screening for fragile X syndrome. Obstet Gynecol 2010;116:1008-1010.
10. Royal Australian and New Zealand College of Obstetricians and Gynaecologists. Prenatal screening and diagnosis of chromosomal and genetic conditions in the fetus in pregnancy 2015. Available at https:// www.ranzcog.edu.au/college-statements-guidelines.html. Accessed on 3 October 2016.

11. Edwards JG, Feldman G, Goldberg J, et al. Expanded carrier screening in reproductive medicine-points to consider: a joint statement of the American College of Medical Genetics and Genomics, American College of Obstetricians and Gynecologists, National Society of Genetic Counselors, Perinatal Quality Foundation, and Society for Maternal-Fetal Medicine. Obstet Gynecol 2015;125:653-662.

12. Acharya $K$, Ross LF. Fragile $X$ screening: attitudes of genetic health professionals. Am J Med Genet A 2009;149A:626-632.

13. Archibald $A D$, Hickerton $C L$, Jaques $A M$, Wake $S$, Cohen J, Metcalfe $S A$. "It's about having the choice": stakeholder perceptions of populationbased genetic carrier screening for fragile $X$ syndrome. Am J Med Genet A 2013;161A:48-58.

14. Anido A, Carlson LM, Taft L, Sherman SL. Women's attitudes toward testing for fragile $X$ carrier status: a qualitative analysis. J Genet Couns 2005;14:295-306.

15. Fanos JH, Spangner KA, Musci TJ. Attitudes toward prenatal screening and testing for fragile X. Genet Med 2006;8:129-133.

16. Skinner D, Sparkman KL, Bailey Jr. DB Screening for fragile $X$ syndrome: parent attitudes and perspectives. Genet Med 2003;5:378-384.

17. Archibald AD, Jaques AM, Wake S, Collins VR, Cohen J, Metcalfe SA. "It's something I need to consider": decisions about carrier screening for fragile $X$ syndrome in a population of non-pregnant women. Am J Med Genet A 2009;149A:2731-2738.

18. Archibald AD, Hickerton CL, Wake SA, Jaques AM, Cohen J, Metcalfe SA. "It gives them more options": preferences for preconception genetic carrier screening for fragile X syndrome in primary healthcare. J Commun Genet 2016;7:159-171.

19. Henneman L, Borry P, Chokoshvili D, et al. Responsible implementation of expanded carrier screening. Eur J Hum Genet. 2016;24: e1-e12.

20. Hill MK, Archibald AD, Cohen J, Metcalfe SA. A systematic review of population screening for fragile X syndrome. Genet Med 2010;12: 396-410.

21. Metcalfe $S$, Jacques $A$, Archibald $A$, et al. A model for offering carrier screening for fragile $X$ syndrome to nonpregnant women: results from a pilot study. Genet Med 2008;10:525-535.

22. Ames AG, Metcalfe $S A$, Archibald AD, Duncan RE, Emery J. Measuring informed choice in population-based reproductive genetic screening: a systematic review. Eur J Hum Genet 2015;23:8-21.

23. Martyn $M$, Anderson $V$, Archibald $A$, et al. Offering fragile $X$ syndrome carrier screening: a prospective mixed-methods observational study comparing carrier screening of pregnant and non-pregnant women in the general population. BMJ Open 2013;3:e003660.

24. Ames $A G$, Jaques $A$, Ukoumunne $O C$, et al. Development of a fragile $X$ syndrome (FXS) knowledge scale: towards a modified multidimensional measure of informed choice for FXS population carrier screening. Health Expect 2012;18:69-80.

25. Marteau TM, Dormandy E, Michie S. A measure of informed choice. Health Expect 2001;4:99-108.

26. van den Berg $M$, Timmermans $D R$, ten Kate $L P$, van Vugt JM, van der Wal G. Informed decision-making in the context of prenatal screening. Patient Educ Couns 2006;63:110-117

27. Crawford JR, Henry JD. The depression anxiety stress scales (DASS): normative data and latent structure in a large non-clinical sample. $\mathrm{Br} J$ Clin Psychol 2003;42:111-131

28. Marteau TM, Bekker $\mathrm{H}$. The development of a six-item short-form of the state scale of the Spielberger state-trait anxiety inventory (STAI). Br J Clin Psychol 1992;31:301-306.

29. O'Connor A. User Manual—Decisional Conflict Scale (16 item statement format). October 20121993 (updated 2010).

30. Janz NK, Becker MH. The Health Belief Model: a decade later. Health Educ Q 1984;11:1-47.

31. O'Connor A. User Manual - Decision Regret Scale. Ottawa Hospital Research Institute: Ottawa, ON, 1996 (modified 2003). http://decisionaid. ohri.ca/docs/develop/User_Manuals/UM_Regret_Scale.pdf. Accessed October 2012

32. Australian Bureau of Statistics. Census. 2011. Available at http://www. abs.gov.au. Accessed on 17 May 2016. 
33. Alfaro Arenas R, Rosell Andreo J, Heine Suner D, Group for the study of FXSitBI. A pilot study of fragile $X$ syndrome screening in pregnant women and women planning pregnancy: implementation, acceptance, awareness, and geographic factors. J Genet Couns 2016;26:501-510.

34. Tambor ES, Bernhardt BA, Chase GA, et al. Offering cystic fibrosis carrier screening to an HMO population: factors associated with utilization. Am J Hum Genet 1994;55:626-637.

35. Ioannou L, Massie J, Lewis S, McClaren B, Collins V, Delatycki MB. 'No thanks': reasons why pregnant women declined an offer of cystic fibrosis carrier screening. J Commun Genet 2014;5:109-117.

36. Grody WW. Where to draw the boundaries for prenatal carrier screening. JAMA 2016;316:717-719.

37. Sheehan J, Sherman KA, Lam T, Boyages J. Association of information satisfaction, psychological distress and monitoring coping style with postdecision regret following breast reconstruction. Psychooncol 2007;16: 342-351.

38. Fu YH, Kuhl DP, Pizzuti A, et al. Variation of the CGG repeat at the fragile $X$ site results in genetic instability: resolution of the Sherman paradox. Cell 1991;67:1047-1058

39. Khaniani MS, Kalitsis P, Burgess T, Slater HR. An improved diagnostic PCR assay for identification of cryptic heterozygosity for CGG triplet repeat alleles in the fragile $X$ gene (FMR1). Mol Cytogenet 2008;1:5.
40. Chen $L$, Hadd $A$, Sah $S$, et al. An information-rich CGG repeat primed PCR that detects the full range of fragile $X$ expanded alleles and minimizes the need for southern blot analysis. J Mol Diagn 2010;12: 589-600.

(i) (-) $€$ This work is licensed under a Creative Commons Attribution-NonCommercial-NoDerivs $\quad 4.0$ International License. The images or other third party material in this article are included in the article's Creative Commons license, unless indicated otherwise in the credit line; if the material is not included under the Creative Commons license, users will need to obtain permission from the license holder to reproduce the material. To view a copy of this license, visit http://creativecommons.org/licenses/ by-nc-nd/4.0/

(C) The Author(s) 2017 